\title{
Observations and model simulations of mixing near the extratropical tropopause
}

\author{
L. L. Pan, ${ }^{1}$ P. Konopka, ${ }^{2}$ and E. V. Browell ${ }^{3}$ \\ Received 11 July 2005; revised 11 October 2005; accepted 7 December 2005; published 9 March 2006.
}

[1] Mixing of stratospheric and tropospheric air plays an essential role in the stratospheretroposphere exchange (STE) of chemical species. Although evidence of mixing is frequently observed, quantifying its effect has been a significant challenge. We present an analysis using both observations and modeling tools to address the issues of where mixing occurs and how models can quantify its effect to STE across the extratropical tropopause. The data are from remote and in situ measurements on board the NASA DC-8 during the Subsonic Assessment: Ozone and Nitrogen Oxides Experiment (SONEX). The model simulations use the Chemical Lagrangian Model of the Stratosphere (CLaMS). Our analyses use tracer correlations together with lidar measurements of ozone cross sections to characterize the spatial extent of the observed mixing. The results also serve to identify the air mass that is involved in an irreversible exchange. Results of the CLaMS simulations of lidar and in situ observations for a case observed on 29 October 1997 demonstrate the model's ability to characterize mixing near the tropopause. The results also indicate that using the shear and deformation in large-scale winds, we can reproduce the observed mixing and the overall features of the stratospheric intrusion. An artificial tracer is used to quantify the transport between the stratosphere and troposphere, to track the preferred location and the cumulative effect of mixing. These results demonstrate progress toward modeling mixing and STE using Lagrangian models and show the potential of the CLaMS model in quantifying the effect of mixing on the chemical composition of the upper tropospheric and lower stratospheric region.

Citation: Pan, L. L., P. Konopka, and E. V. Browell (2006), Observations and model simulations of mixing near the extratropical tropopause, J. Geophys. Res., 111, D05106, doi:10.1029/2005JD006480.

\section{Introduction}

[2] Stratosphere-troposphere exchange (STE) across the extratropical tropopause plays an important role in the chemical distribution and chemical processing in the upper troposphere and lower stratosphere (UTLS). Because of the large gradients in ozone and water vapor across the midlatitude tropopause, the two-way exchange is especially important for these two radiatively important trace gases in the extratropical UTLS region. Understanding the controlling mechanisms of STE is therefore an essential component for chemistry-climate coupling studies and for predicting global change. To quantify the dynamical effect on the chemical composition in the UTLS region, we need to develop modeling tools that are capable of reproducing observed STE events and diagnosing the controlling mechanisms. In this paper, we address the issues of mixing across the extratropical tropopause using a combination of observations and modeling tools. In particular, we focus on the need for reproducing observed mixing using models and further

\footnotetext{
${ }^{1}$ National Center for Atmospheric Research, Boulder, Colorado, USA.

${ }^{2}$ Institute for Stratospheric Chemistry (ICG-I), Juelich, Germany.

${ }^{3}$ NASA Langley Research Center, Hampton, Virginia, USA.
}

Copyright 2006 by the American Geophysical Union. 0148-0227/06/2005JD006480 quantifying its effect on the exchange of chemical tracers between upper troposphere and lower stratosphere.

[3] Physically, the two-way exchange process results in mixing between stratospheric and tropospheric air. Observationally, "mixing lines," measurements of a pair of chemical tracers with a range of transitional values between that of the stratosphere and troposphere in tracer-tracer space, are often used as evidence of irreversible STE. Mixing in the tropopause region is frequently observed. In particular recent aircraft in situ measurements provided abundant evidence of mixing near the extratropical tropopause using correlations of ozone-carbon monoxide $\left(\mathrm{O}_{3}-\mathrm{CO}\right)$ [Zahn et al., 2000; Fischer et al., 2000; Pfister et al., 2002; Hoor et al., 2002, 2004; Pan et al., 2004]. These observed mixing lines, while indicating the occurrence of mixing between stratosphere and troposphere air mass, are often obscure in providing quantitative information on STE. It is often difficult to characterize, on the basis of mixing lines alone, the spatial range that is influenced by the twoway exchange.

[4] There has been a long history of observing STE associated with cutoff cyclones and tropopause folds [e.g., Danielsen, 1968; Shapiro, 1980; Browell et al., 1987; Wimmers et al., 2003; Flentje et al., 2005], but it is often not clear how much irreversible exchange has occurred for each event on the basis of observed snapshots [World 
Meteorological Organization, 1986]. In this paper, we present an analysis of mixing near the subtropical jet (STJ) using both in situ measurements of tracer-tracer correlations and the simultaneously measured ozone atmospheric cross sections along the flight track (curtains), and static stability profile curtains. These detailed analyses of mixing with chemical and thermal background information help connect the occurrence of mixing between the tracertracer space and the physical space and demonstrate an effective method for identifying and characterizing the air mass involved in the irreversible exchange.

[5] The most important goal of this study is to investigate how we can quantify the effect of mixing on the exchange of chemical tracers on a global scale. For this purpose, we examine the application of the Chemical Lagrangian Model of the Stratosphere (CLaMS) in the extratropical tropopause region. Recent STE studies have shown that using Lagrangian models in general has several advantages. By analyzing air parcel trajectories, we can identify preferred exchange locations. Using Lagrangian models, the spatial and temporal patterns of the regions influenced by STE have been characterized [Wernli and Bourqui, 2002; Stohl, 2003, and references therein]. To take this effort one step further, we address the issues of how to represent the irreversibility (caused by mixing) in the transport process and what key physical mechanisms cause the mixing. These are important issues for quantifying STE flux and distribution of the chemical tracers. Since the air parcels' chemical properties will change during advection when mixing occurs, a pure advection based calculation is limited in representing the chemical characteristics of the parcels and in quantifying chemical exchange. These reasons are the impetus for using the CLaMS model in the extratropical tropopause region.

[6] CLaMS is a three dimensional Lagrangian chemical transport model that includes advection and parameterized mixing [McKenna et al., 2002a, 2002b; Konopka et al., 2004, 2005]. This model allows a simple comparison of calculated STE with and without mixing, which makes it an excellent tool for diagnosing the importance of mixing. Comparisons of modeled and observed mixing lines provide a physical mechanism of evaluating the mixing algorithm used in CLaMS. Since mixing in the model is controlled by the shear and strain in the large-scale wind fields, the comparisons will also provide information on the significance of the large-scale wind fields as a controlling mechanism for mixing.

[7] This paper is divided into seven sections. Following the introduction, we present a data description in section 2, and a model description in section 3. Data analyses based on measurements are given in section 4. Results from the model simulation and comparisons with the observations are given in section 5 . In section 6 , we demonstrate the use of CLaMS stratospheric tracer in characterizing the effect of mixing on the UTLS composition. Discussion and conclusions are given in section 7.

\section{Data Description}

[8] The measurements used in this study are from the NASA-sponsored Subsonic Assessment: Ozone and Nitrogen Oxides Experiment (SONEX) [Singh et al., 1999]. The main objective of SONEX was to understand $\mathrm{NO}_{\mathrm{x}}$ sources, including that from the current subsonic aircraft fleet in the North Atlantic, with and without convection. The airborne campaign was conducted using NASA DC-8 aircraft during October-November 1997, with 17 flights between Bangor, Maine, Shannon, Ireland, and Azores, Portugal. In this study, we used the remote sensing measurements of ozone and temperature and the in situ measurements of ozone and $\mathrm{CO}$.

[9] The remote sensing ozone profiles were measured along the aircraft flight track by the NASA Langley airborne Differential Absorption Lidar (DIAL) system [Browell et al., 1983, 1998]. The vertical resolutions of the ozone profile measurements were $300 \mathrm{~m}$ (nadir) and $500 \mathrm{~m}$ (zenith). The horizontal resolution was $12 \mathrm{~km}$ (1 min average). The measurement accuracy was better than $10 \%$ or 2 ppbv (whichever is larger).

[10] The temperature profile and tropopause data were from JPL DC8 Microwave Temperature Profiler (MTP), which is a passive microwave radiometer that measures the natural thermal emission from oxygen molecules at three frequencies $(55.51,56.66$ and $58.79 \mathrm{GHz})$. The vertical resolution of the profiles was $\sim 0.2 \mathrm{~km}$ within $\sim 2 \mathrm{~km}$ of the aircraft, decreasing with distance to $\sim 2 \mathrm{~km}$ at $10 \mathrm{~km}$ from the aircraft. For flight altitudes of 10 to $12.5 \mathrm{~km}$, the MTP aboard the NASA DC-8 exhibited a postmission validated accuracy of $<1.0 \mathrm{~K}$ throughout the altitude region 8.5 to $16.5 \mathrm{~km},<2.0 \mathrm{~K}$ from 5 to $21 \mathrm{~km}$, and $<3.0 \mathrm{~K}$ from 4 to $26 \mathrm{~km}$.

[11] The DC-8 in situ CO measurements are from DACOM, a tunable diode laser spectrometer [Sachse et al., 1987] with $\sim 1$ s sampling rate. The accuracy of the measurement was $\sim 2 \%$. The in situ ozone measurements were from a chemiluminescent technique with an estimated 1 ppbv accuracy [Singh et al., 1999].

[12] For synoptic-scale meteorological background information, we used the wind fields and potential vorticity calculated from the European Centre for Medium-Range Weather Forecasts (ECMWF) analyses. The version of the ECMWF data we used was based on a T63 analysis mapped to a 1.25 by 1.125 degree grid in latitude and longitude.

\section{Model Description}

[13] The CLaMS model is the first chemistry transport model based on Lagrangian transport where the concept of a deformation-induced mixing was successfully realized both in 2 and 3 dimensions. The successful application of CLaMS in the polar stratosphere has demonstrated the model's ability to simulate filamentary structure of chemical tracers and mixing across the polar vortex edge [McKenna et al., 2002a; Konopka et al., 2004].

[14] CLaMS uses an ensemble of air parcels to serve as a time-dependent irregular grid. The positions of these parcels at a given time are determined by $3-\mathrm{D}$ trajectory calculations. Unlike other trajectory models that use pure advection, CLaMS allows these parcels to mix, resulting in a change in the chemical composition of the parcels. The mixing is controlled by a physically based mechanism using the local horizontal strain and vertical shear rates of the wind fields. The parameters used to control mixing are chosen to optimize the agreement with the observations. The isentropic and cross-isentropic advection in CLaMS is 
a

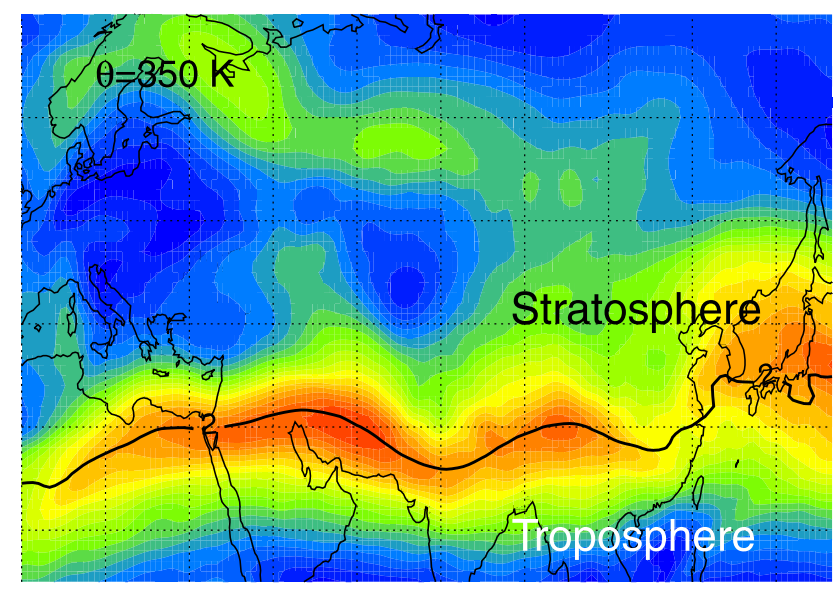

b

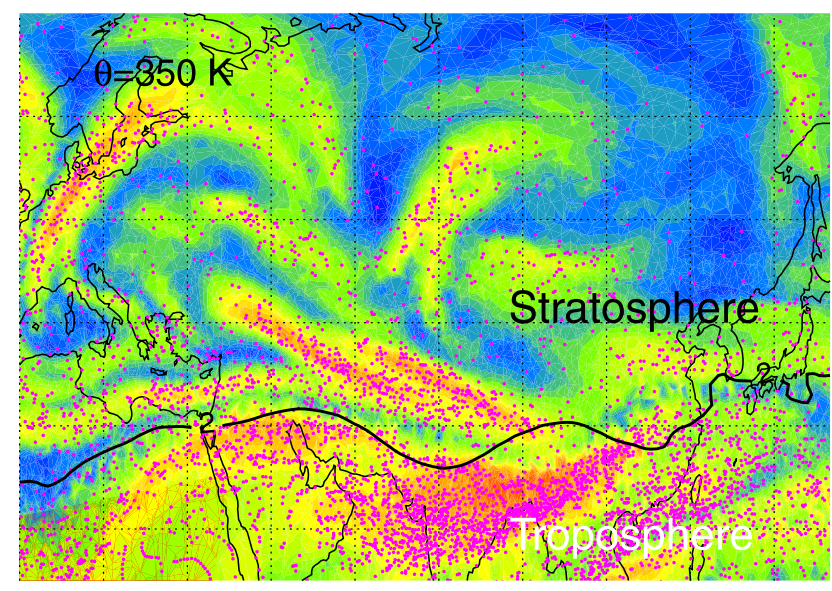

Hor. wind $[\mathrm{m} / \mathrm{s}]$

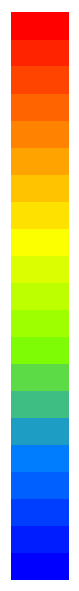

80.

72.

64.

56.

48.

40.

32.

24.

16.

8.

0 .

$\lambda\left[\right.$ day $\left.^{1}\right]$

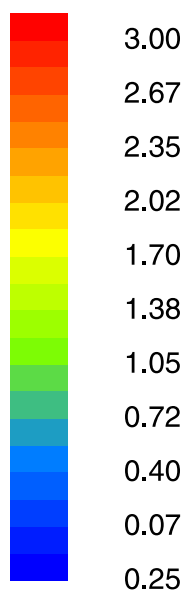

Figure 1. (a) Horizontal winds at $350 \mathrm{~K} \theta$ level for 15 January 2000 at 1200 UTC, derived from the ECMWF analysis with the spatial resolution $1.125 \mathrm{deg}$ (T106). The black contour (PV=2 PVU) denotes the tropopause. (b) Associated flow deformation, represented by the Lyapunov exponent, $\lambda$, calculated over 24 hours (starting from 20020114, 1200 UTC) in the CLaMS layer 345-355 K. The pink dots denote the new ClaMS air parcels generated by mixing.

driven by analyzed winds, currently data from the ECMWF, and heating/cooling rates derived from a radiation calculation, respectively. The chemistry module, which calculates the change of chemical composition of the air parcels due to gas phase and heterogeneous chemistry, is described by McKenna et al. [2002b]. In this study, we used the dynamics package only and included no chemistry.

[15] The horizontal and the vertical density of the grid points are set by choosing the mean distance between the air parcels. The mean horizontal distance, $\mathrm{r}_{0}$, and the vertical distance $\Delta z / 2$, are related by the aspect ratio $\alpha=2 r_{0} / \Delta z$. After initialization of the model, each of the transport steps consists of two parts: pure advection along the calculated trajectories and subsequent mixing. The time interval of pure advection, $\Delta \mathrm{t}$, has typical values varying between 6 and 24 hours. Mixing in the model results from the adaptive regridding (with the frequency $1 / \Delta \mathrm{t}$ ) and associated interpolations that provide the chemical and dynamical properties of the new air parcels. The parameters controlling the deformation-induced mixing are: the critical Lyapunov exponent $\lambda_{c}$ (only flow deformations that are stronger than a certain threshold value, i.e., with the Lyapunov exponents $\lambda$ larger than a critical value $\lambda_{c}$, are mixing-relevant), grid adaptation frequency $1 / \Delta \mathrm{t}$, and the spatial resolution of the model, i.e., approximately the mean horizontal $r_{0}$ and vertical separation $\Delta \mathrm{z}$ between the air parcels.

[16] Physically, the mixing scheme used in CLaMS incorporates into the model the effect of stretching to the change in the air mass in the small scale from the flow deformations produced by the large-scale wind field. The mean distance between the air parcels, $\mathrm{r}_{0}$, can be viewed as the radius of a circularly shaped air parcel before stretching. $\lambda \Delta \mathrm{t}$ defines the eccentricity of the ellipse of the deformed air parcel as a result of stretching. Mixing occurs in the model grid when the critical eccentricity, $\lambda_{x} \Delta \mathrm{t}$, is reached. The choice and validation of the model parameters to properly incorporate the effect of this type of stretching in the stratosphere have been described in detail by Konopka et al. [2004]. The physical meaning of the mixing parameters that reproduce the observed mixing in the vicinity of the winter polar jet have also been discussed using stratospheric observations [Konopka et al., 2005]. In the extra- 


\section{ECMWF PV 971020 340K level ECMWF PV 971029 340K level}

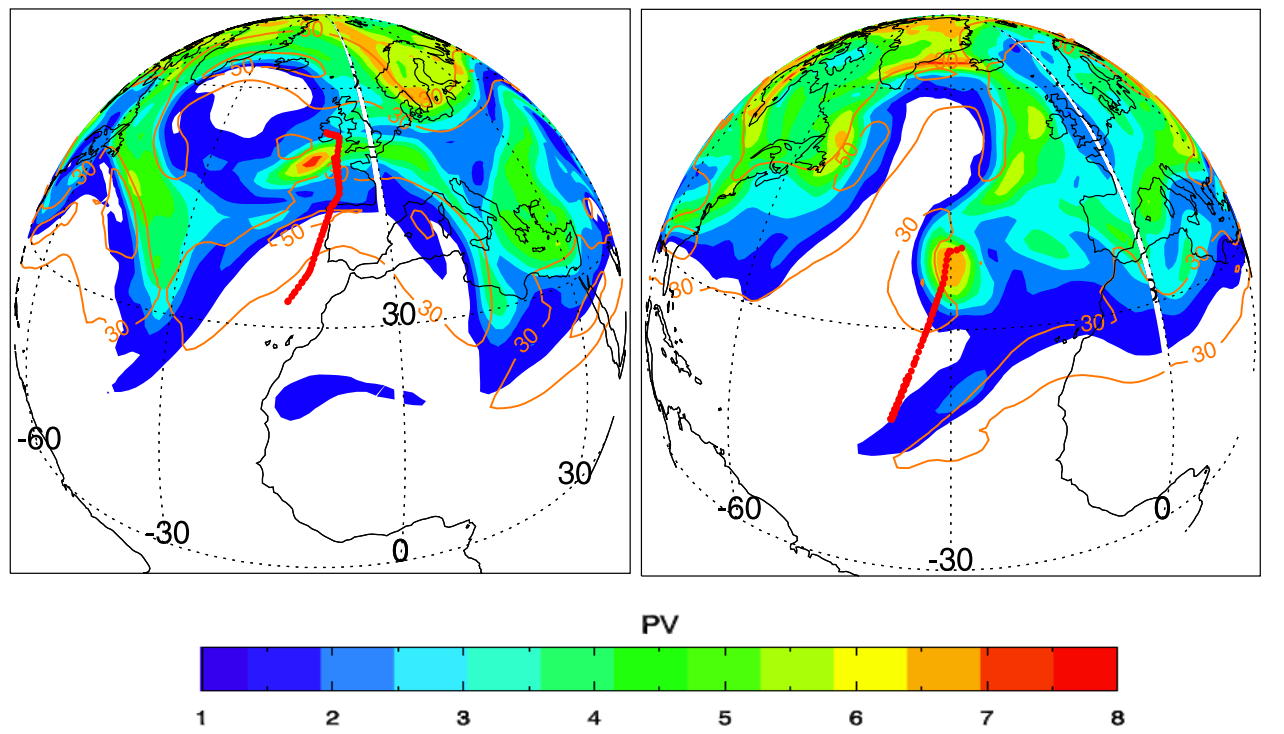

Figure 2. DC-8 flight tracks (red line) for (left) flight 6 (971020) and (right) flight 10 (971029) and $340 \mathrm{~K}$ surface PV map. The PV field is calculated from the ECMWF data for 1200 UTC 20 October and 1800 UTC 29 October. The magnitude of the horizontal wind (orange contours, in $\mathrm{m} / \mathrm{s}$ ) shows the position of the subtropical jet.

tropical UTLS region, we expect that the role of the upper level jets to be similar to that of stratospheric polar-night jet. To illustrate the physical processes incorporated by the numerical scheme of the model, we use an example (Figure 1) to show the relationship of large-scale wind field and the occurrence of mixing in CLaMS.

[17] Figure 1a shows the horizontal wind field on $350 \mathrm{~K}$ isentrope for 15 January 2000 (a date arbitrarily chosen). A strong subtropical jet (STJ) can be seen over the Himalayas. The tropopause is defined as the PV $=2$ PVU surface, which roughly cuts the jet in the middle (black line). Figure $1 \mathrm{~b}$ shows the finite time Lyapunov exponent, $\lambda$, calculated over a time step of 24 hours with the mean horizontal distance of the air parcels, $\mathrm{r}_{0}$, to be $100 \mathrm{~km}$ and randomly distributed over the $350 \pm 5 \mathrm{~K}$ potential temperature range with aspect ratio $\alpha=250$. As indicated by the Figure 1b, the STJ is a source of deformations. In the flanks of the jet, a combined effect of horizontal strain and vertical shear produces the high deformation rates (large $\lambda$ ). The pink dots mark the new air parcels resulted from the regridding, where the critical Lyapunov exponent, $\lambda_{c}$, $\left(\lambda_{c}\right.$ is 1.5 in this case) is reached. Note these points represent both new grid point inserted between two old grid points and those resulted from merging two old grid points, so the total number of grid points stay roughly constant.

[18] This example shows that the range of physical mechanisms incorporated in the ClaMS mixing largely depends on the wind fields used to drive the model. Typically, this implies the large-scale balanced wind dominates the mechanisms of mixing modeled. For the same reason, as all other trajectory models experience, the model will have larger error in the region the wind field is poorly represented in the meteorological analyses data.
[19] For this initial application of CLaMS in the tropopause region, we focus on the following two objectives. First, we examine the effectiveness of this model, developed for stratospheric studies, in simulating mixing in the UTLS region. Second, we examine the role of large-scale winds in controlling the chemical composition in the tropopause region.

\section{Observations of Mixing in the Vicinity of the STJ}

[20] Two examples of mixing observations in the vicinity of the STJ are presented in this section. These two examples are from SONEX flights on 20 and 29 October 1997. The comparison of the two cases provides a sense of what the common features of intrusions are. Several categories of data are presented to provide different perspectives of each event. Ozone curtain data from the airborne DIAL lidar measurements provide the perspective of the chemical distribution in and around the STJ. Winds and potential vorticity (PV) fields are presented to show the related dynamical characteristics. Potential temperature and its lapse rate are presented to show the thermal structure near the STJ and the transition from stratosphere to troposphere. We then examine flight 10 (971029) in more detail, using the time series of in situ tracer data and the tracer-tracer relationship of ozone and $\mathrm{CO}$ to identify the chemical transition between the stratospheric and tropospheric air masses and the irreversible exchange. Model simulations for this case will be discussed in section 5 .

[21] Figure 2 displays the DC-8 flight track of these two SONEX flights on the $340 \mathrm{~K} \mathrm{PV}$ map. Contours of horizontal wind are used to highlight the position of the STJ. Figure 2 shows that both flights sampled in the vicinity 

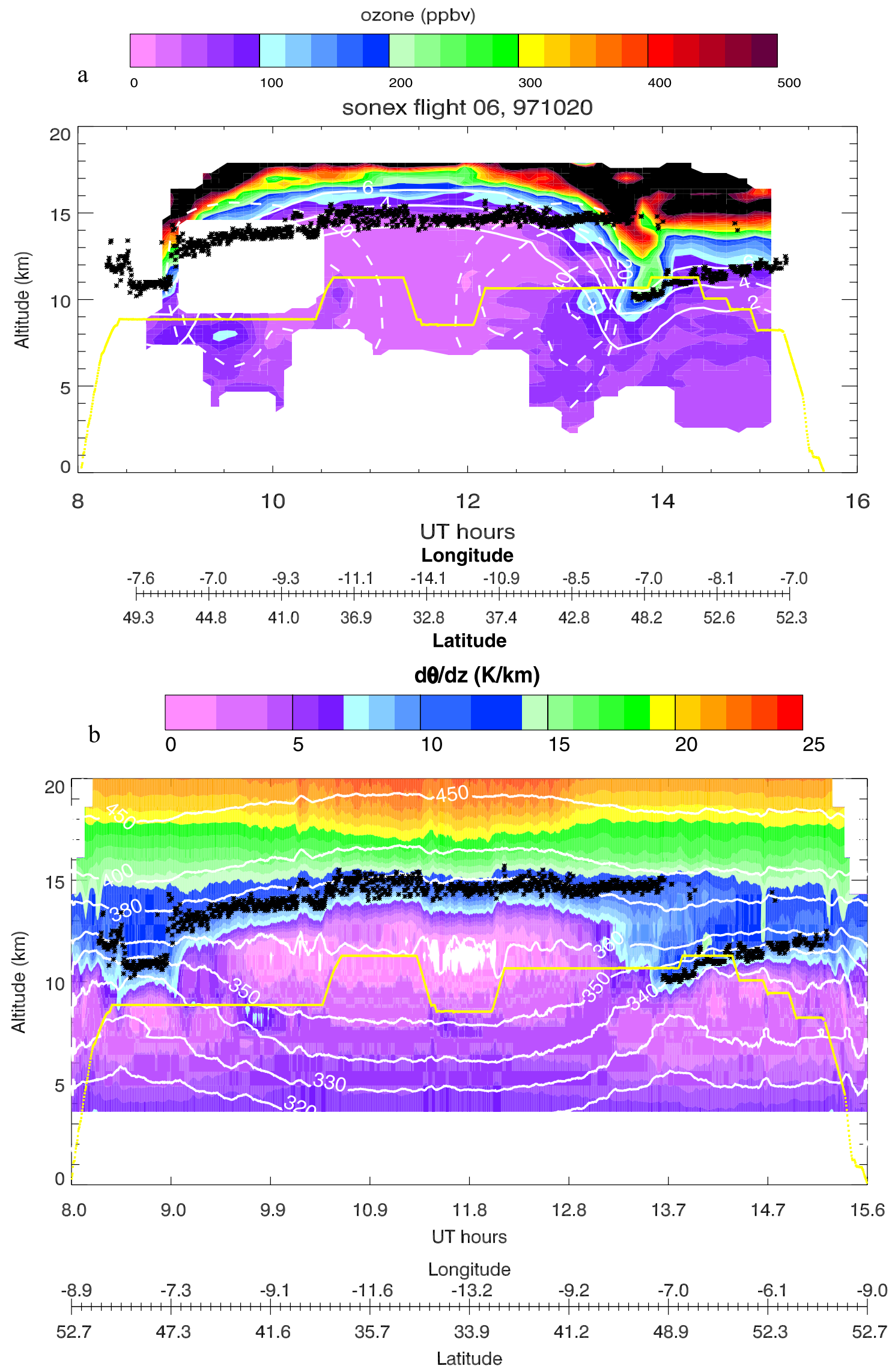

Figure 3 
of subtropical cutoff cyclones. Flight 6 (971020) was based from Shannon, Ireland $\left(52.7^{\circ} \mathrm{N}, 8.9^{\circ} \mathrm{W}\right)$. The DC-8 took off around $0800 \mathrm{UTC}$, flew south to around $32^{\circ} \mathrm{N}$ and returned around 1500 UTC. The DC-8 was at several different altitudes to sample the upper troposphere chemical composition and the impact of the air traffic. Flight 10 (971029) was based from the Azores, Portugal $\left(38.8^{\circ} \mathrm{N}, 27.1^{\circ} \mathrm{W}\right)$. The DC-8 took off around 1100 UTC and flew southwest to around $20^{\circ} \mathrm{N}$ then returned around 1900 UTC. In both flights, the DC8 transected the STJ twice. The airborne DIAL measured ozone profiles with both nadir and zenith viewing geometry and provided the vertical ozone cross sections for the UTLS region across the STJ. The MTP instrument measured the temperature profile curtain, which allows examination of the thermal structure together with the chemical structure for the region near the jet. Observations made on flight 6 (971020) are presented in Figure 3; and the data for the flight 10 (971029) are presented in Figures 4 and 5.

[22] Figure 3 shows a comparison of the chemical characteristics and the thermal structure of the air around the STJ. Displayed in Figure $3 \mathrm{a}$ are the ozone curtain (color image) with PV (solid contours) and zonal wind (dashed contours) from the ECMWF data. Figure 3 b shows the static stability (given in $\mathrm{d} \theta / \mathrm{dz}$ ) distributions (color image) and the isentropes from the MTP measurements. The thermal tropopause derived from the MTP temperature data (small black crosses) and the DC-8 flight altitudes are shown in both panels. As shown in Figure 3a, a tongue of stratospheric air marked by high ozone values developed on the cyclonic side of the jet and where the thermal tropopause has a break. A separated region of high ozone (ozone greater than $100 \mathrm{ppbv}$ ) is shown to be detached from the tongue in the cross section, suggesting irreversible transport of ozone into the troposphere. Surrounding areas of the upper troposphere also show elevated ozone levels, indicating the broad region of impact from the intrusion. Figure 3 also shows that the chemical transition between the stratosphere and troposphere, represented by the ozone values of 100-350 ppbv, forms a fairly compact layer, typically around $2 \mathrm{~km}$ thick, but it expands to $\sim 5 \mathrm{~km}$ on the poleward side of the jet. This is consistent with the statistical study of tracer-tracer relations [Pan et al., 2004]. Similar features exist in the thermal structure, as shown in Figure 3b, indicated by the transitional values of $\theta$ lapse rate (represented by blue colors). The range of transition is selected empirically to cover both the upper and the lower tropopause on two sides of the STJ.

[23] Similar to Figure 3, Figure 4 shows the ozone profile curtain and the thermal structure as measured by DIAL and MTP for the 29 October flight. During this flight, the DC-8 took off from the Azores while there was a cutoff low just west of Azores. The feature of the cutoff low is evident in both panels before $\sim 1350$ UTC and between $\sim 1750$ UTC and 1850 UTC on the cyclonic side of the jet core. The thermal structure, from MTP data, suggests a double tropopause inside the cutoff low, the dynamic tropopause (2-3 PVU contour) shows a significant depression to as low as $\sim 6 \mathrm{~km}$ in altitude. Ozone data show an elevated level of ozone in the surrounding troposphere, with features suggesting irreversible stratosphere to troposphere transport.

[24] To further identify the transition between stratosphere and troposphere and the air mass involved in the irreversible exchange, we focus on the second example and examine the in situ tracer data. The irreversibility can be identified by whether the mixing of stratospheric and tropospheric air has occurred. In situ measurements of multiple tracers on board DC-8 are available for this analysis. Figure 5 shows the time series of ozone and $\mathrm{CO}$ measured during the flight and their relationship in tracertracer space. The time series, together with the ozone curtain data, shows the contrast of the air mass in and out of the cutoff low with high ozone and low CO inside, indicating stratospheric characteristics, and vice versa outside. The clear distinction of air mass characteristics is also shown in the tracer-tracer space between the measurements in and out of the cutoff low. It is interesting to contrast the measurements in the physical space and the tracer-tracer space. The measurements between 1250 and 1700 UT, more than 3/4 of the flight, are compressed into a small region in the tracer-tracer space (roughly $40-80$ ppbv of ozone and $80-$ $100 \mathrm{ppbv}$ of $\mathrm{CO}$ ). The measurements near the cutoff low, although representing a small segment of the flight, expand in the tracer space to show prominent mixing lines between stratospheric and tropospheric air.

[25] The mixing lines shown in Figure 5 are frequently observed in the airborne measurements. They have been used as observational evidence of STE, however, previous studies have not diagnosed the spatial extent of the air mass involved in mixing. This diagnosis can be done for the example in hand, because we have both in situ and the lidar curtain data, which provide a broader 2-D background of the flight. We focus on the part of the flight 10 between 1700 and 1870 UTC when the DC- 8 transected the cutoff low the second time. Figure 6 shows the $\mathrm{O}_{3}-\mathrm{CO}$ relationship, the $\mathrm{O}_{3}$ cross section, and the $\theta$ lapse rate for this time segment. To connect the tracer space with the geophysical space, we have labeled, using a set of letters, the positions of key observational points on the flight path and the corresponding points in tracer space. Evidently, mixing occurred at both edges of the cutoff low, between point A and $\mathrm{B}$, and between $\mathrm{C}$ and $\mathrm{D}$, indicated by long mixing lines. The air mass remains largely stratospheric between point $\mathrm{B}$ and $\mathrm{C}$, which shows as a small compact region in the tracer space. Although the onboard tracers did not provide direct information over the entire cutoff low cross section given by the ozone lidar, it is plausible to conclude, on the basis of the end point of the mixing line in Figure 6, that mixing has occurred in the part of the air mass with ozone less than $\sim 350 \mathrm{ppbv}$. In other words, if the region of 8-12 km were sampled between 1750 and $1850 \mathrm{UT}$, we

Figure 3. Lidar ozone and MTP data derived d $\mathrm{d} / \mathrm{dz}$. (a) Ozone mixing ratios (color image), ECMWF based PV contours (solid white) and ECMWF zonal wind (dashed contours). (b) Potential temperature lapse rate derived from MTP data (color image) and the isentropes (white contours). In both Figures $3 \mathrm{a}$ and 3b, small black crosses give the thermal tropopause derived from the MTP data, and the yellow line marks the DC-8 flight altitude. 

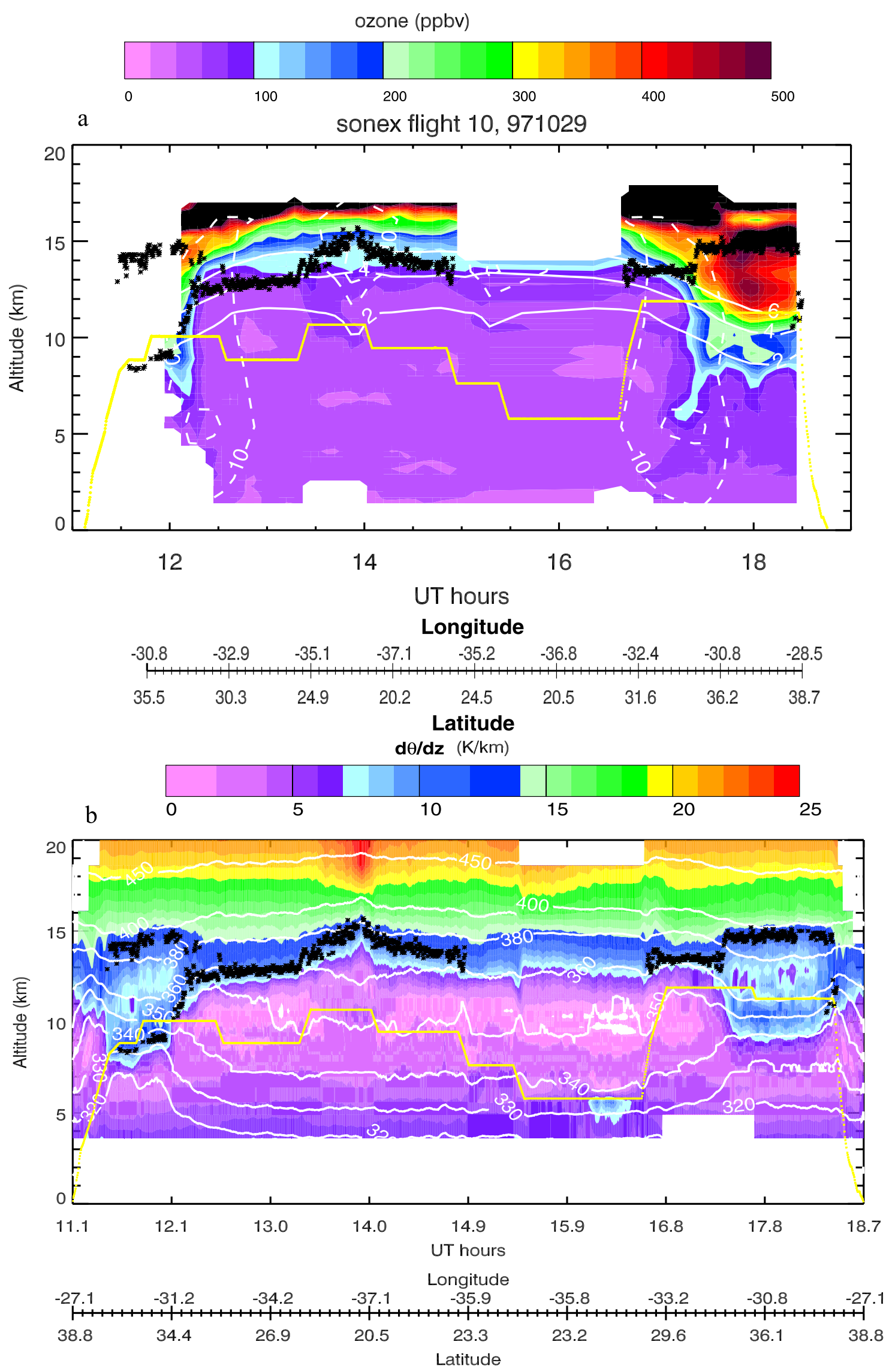

Figure 4 
Flight 10, 19971029

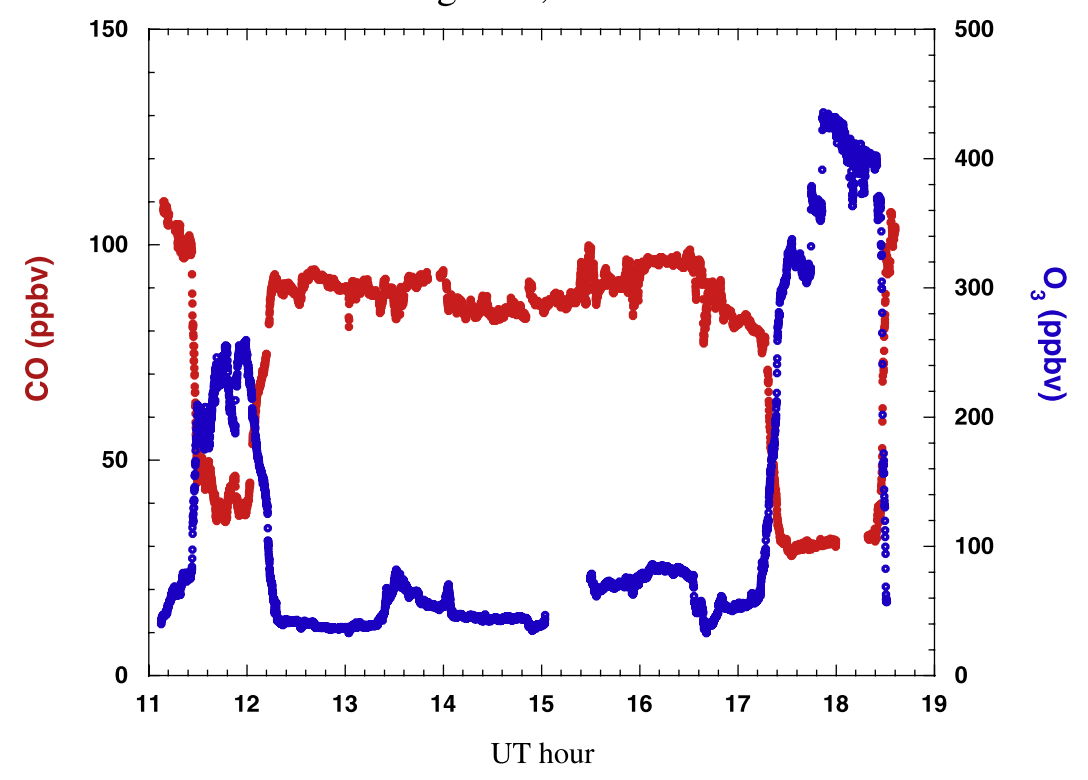

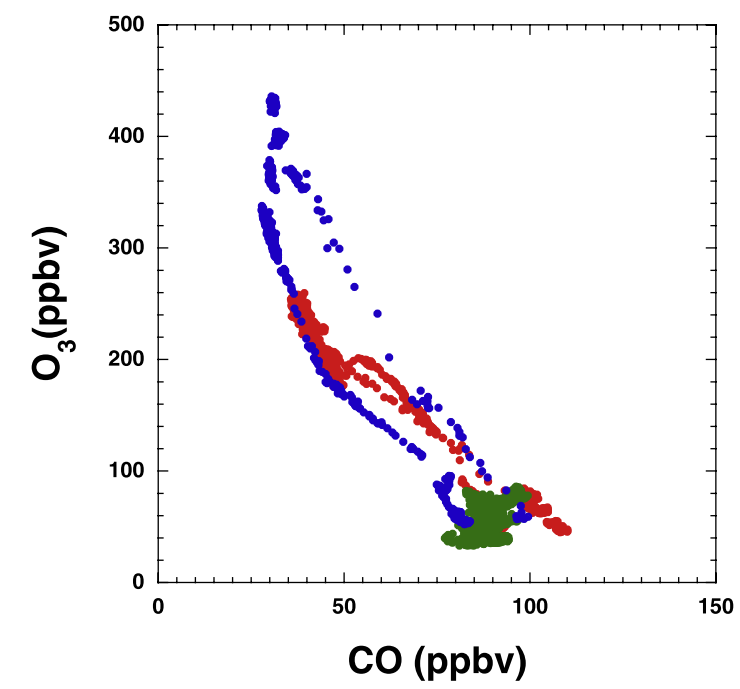

Figure 5. Time series of in situ measurements of (top) $\mathrm{CO}$ and $\mathrm{O}_{3}$ and (bottom) $\mathrm{O}_{3}$-CO relationship on board DC-8 for 971029. The colors in Figure 5 (bottom) are used to mark different segments of the flight.

expect the air mass to show similar characteristics in the tracer space as shown in Figure 6 (top).

[26] It is interesting to note that the $\mathrm{AB}$ and $\mathrm{CD}$ mixing lines on two side of the cutoff low show slightly different characteristics, with CD (sampled vertically) more of a straight line, consistent with direct mixing of air mass between the two end points. AB (sampled horizontally) on the other hand has a kink in the middle, suggesting additional origins involved in mixing. We note that the sampling path of $\mathrm{CD}$ is a part of the aircraft descent and it coincides with a region where the isentropes, as shown in Figure 6 (bottom), are almost vertical, as part of a wave structure. The wavelength of this wave structure is $\sim 100 \mathrm{~km}$ and consistent with gravity waves. Also note that the static stability in the CD segment was very low which provides the conditions of rapid vertical mixing. We do not have enough information to conclude whether the apparent vertical mixing is a result of gravity wave breaking, but this is of interest for future investigations.

[27] The above examples show that mixing is an important part of irreversible transport of chemical tracers. Representing mixing in models is a critical step for understanding the mechanism of mixing and quantifying irreversible transport. In the following section, we present

Figure 4. ( $\mathrm{a}$ and b) Same as Figure 3 for flight 10 (971029). During the second transact of the cutoff low, MTP data hinted a lower tropopause near $9 \mathrm{~km}$ (B. Gary, private communication, 2004). This lower tropopause is evident in the static stability plot. We have used a dashed line to indicate this lower tropopause. 

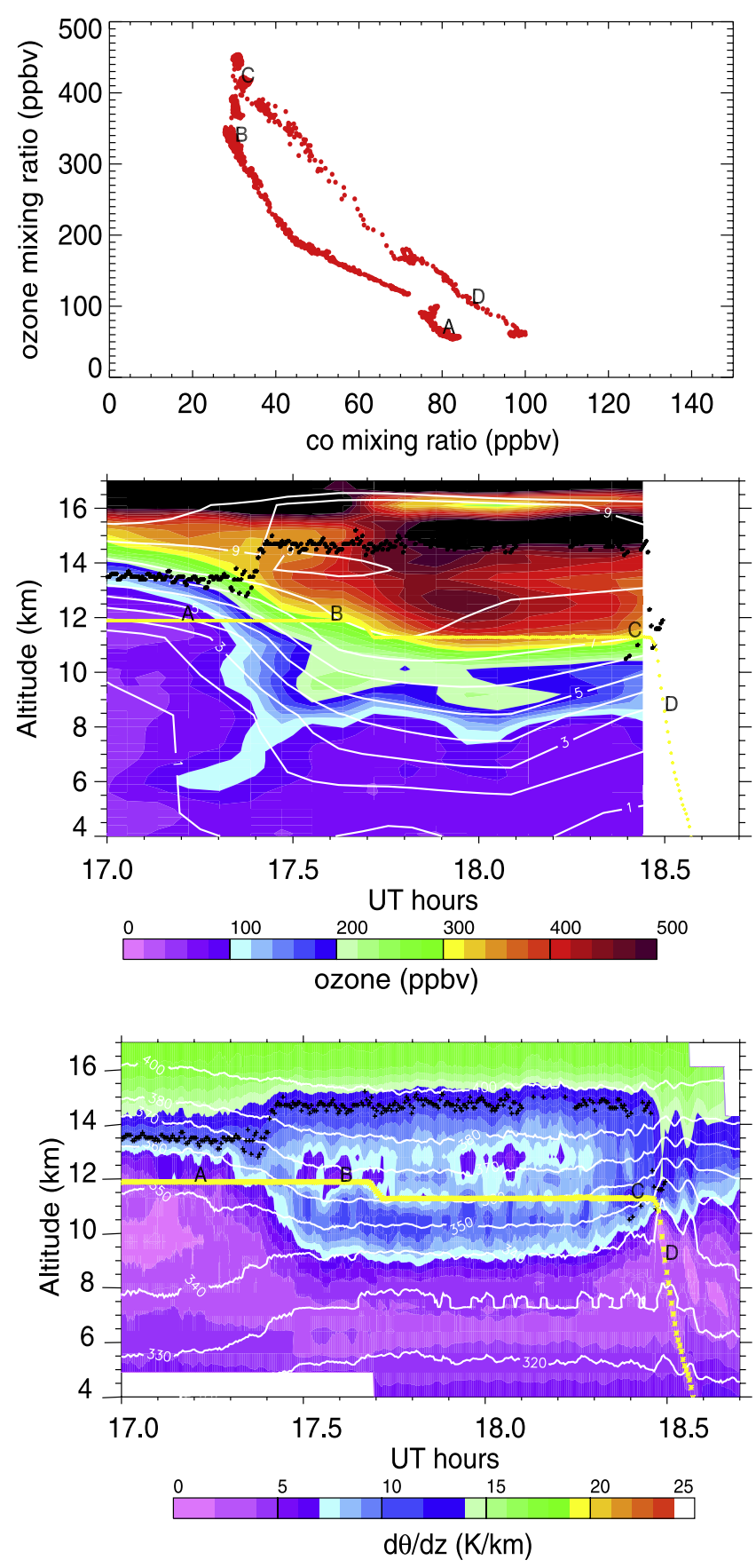

Figure 6. (top) $\mathrm{O}_{3}-\mathrm{CO}$ for the flight segment between $1700 \mathrm{UTC}$ and $1870 \mathrm{UTC}$, in comparison with the (middle) ozone curtain and (bottom) $\theta$ lapse rate curtain same as in Figure 4. In all three panels, letters A, B, C, and D mark the measurements at 1720,1760, 1840, and $1850 \mathrm{UTC}$, respectively.

a simulation of the flight 10 (971029) observations using CLaMS.

\section{Model Simulation for SONEX Flight 10, 971029}

[28] The observed stratosphere intrusion around the STJ and subsequent mixing is controlled by physical mecha- nisms over a range of scales. Synoptic-scale disturbances, induced by baroclinic instability, are known to be chiefly responsible for the development of the PV anomalies near the jet [Holton et al., 1995, and references therein]. The subsequent mixing is produced by several mechanisms including radiative erosion induced by diabatic heating/ cooling [e.g., Lamarque and Hess, 1994], turbulent mixing induced by dynamical or convective instability, or gravity wave breaking [e.g., Cho et al., 1999]. In the following case study of simulating mixing, the deformation in the largescale wind fields is the only parameter we used in the model to control mixing. How well the overall features of observed
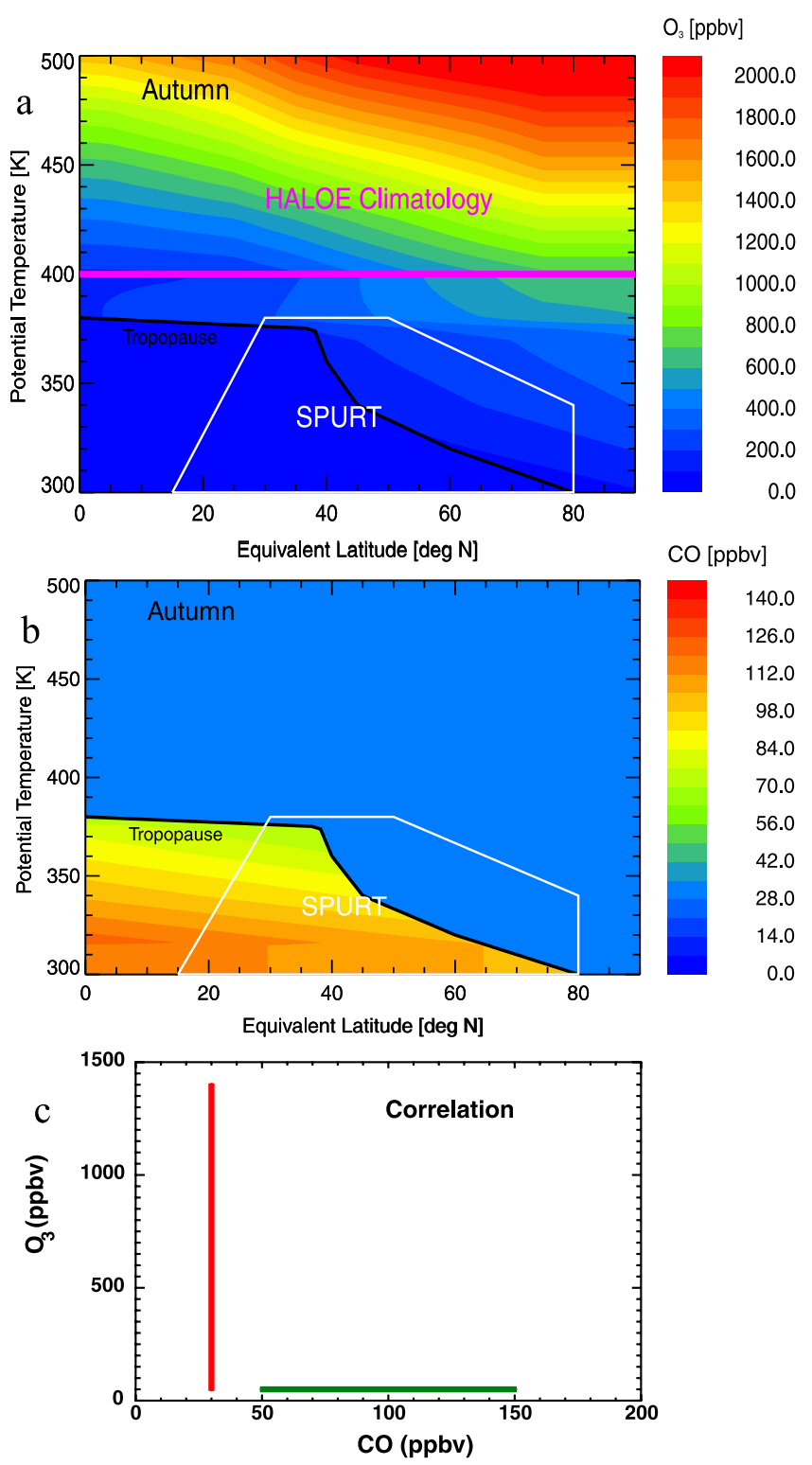

Figure 7. Initial conditions used for (a) ozone and (b) $\mathrm{CO}$ for the CLaMS simulation. The stratospheric ozone is based on a HALOE measurement equivalent latitude zonal mean. The tropospheric CO used a climatology based on the SPURT campaign. (c) The ozone is set to be a constant in troposphere (50 ppbv), and likewise, CO is chosen as $30 \mathrm{ppbv}$ for lowermost stratosphere to provide the initial conditions for the tracer-tracer relationship. 

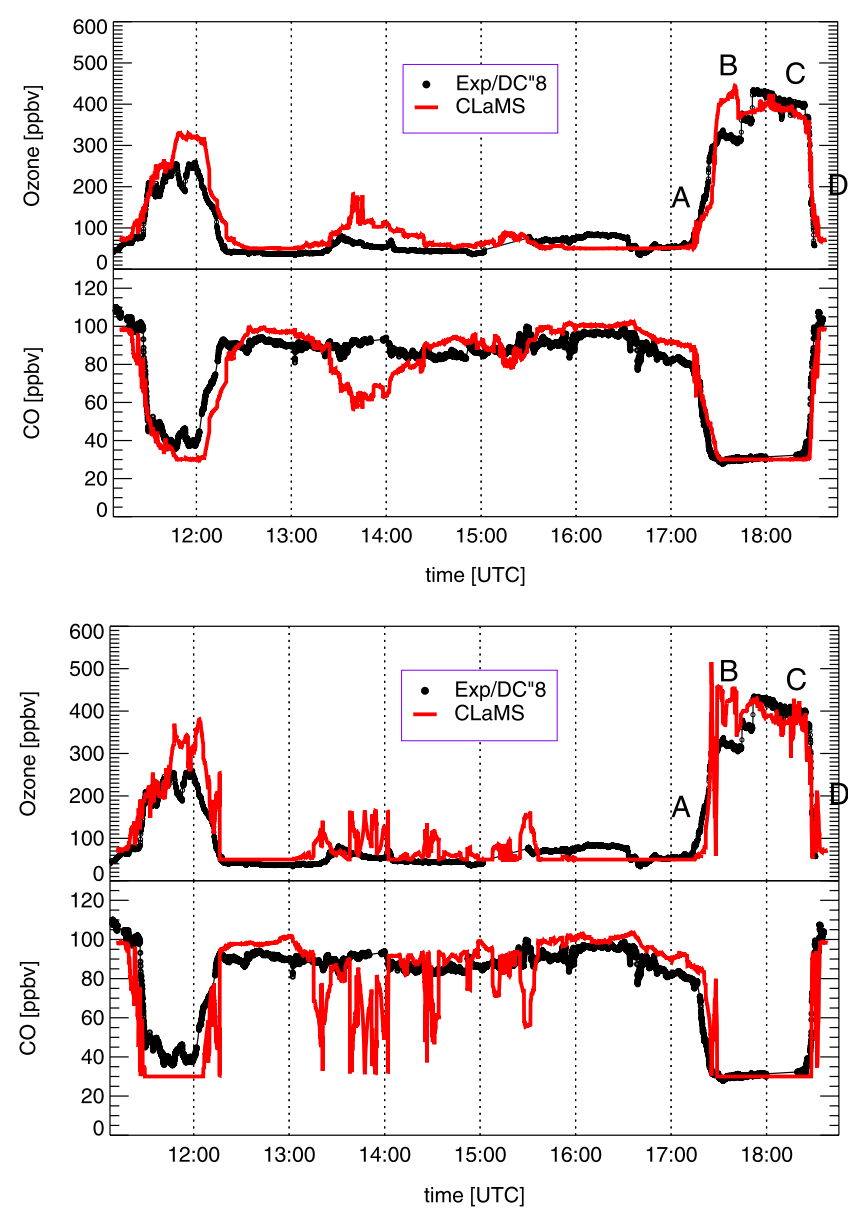

Figure 8. CLaMS simulation of the time series of ozone and $\mathrm{CO}$, as in Figure 5. Result of (top) advection with mixing and (bottom) pure advection.

intrusions and the mixing are reproduced by the model provides information on the role of large-scale dynamical processes in producing the fine-scale mixing.

[29] To simulate the observed ozone and the tracer relationship, we initiate the ozone and $\mathrm{CO}$ fields using an observation based equivalent latitude zonal mean structure and a simple $\mathrm{O}_{3}-\mathrm{CO}$ relationship, as shown in Figure 7. In the stratosphere, we initiate ozone according to a climatology combining HALOE data and recent aircraft in situ measurements [Grooß and Russell, 2005; Krebsbach et al., $2006]$ and keep $\mathrm{CO}$ at a constant value (30 ppbv). In the troposphere, we initiate $\mathrm{CO}$ using a climatology based on airborne measurements during the SPURT campaign [Hoor et al., 2004] and use a constant value for ozone (50 ppbv). Several tropopause definitions were tried in the process. The results shown used a PV gradient-based tropopause definition, similar to the selection of the polar vortex edge [Nash et al., 1996], for the region poleward of the STJ and interpolated to the $380 \mathrm{~K}$ isentrope for the tropics. Only the northern hemisphere is included in the model runs. The key feature of the initial conditions is the " $L$ " shaped simple $\mathrm{O}_{3}$-CO relationship, as shown in Figure 7c.

[30] We have also designated an inert stratospheric tracer, initiated as 1 above the tropopause and 0 below. Throughout the simulation and at the end, the value of this tracer will help track mixing between stratosphere and troposphere and provide quantitative information on the cumulative effect of mixing in the air mass.

[31] With this oversimplified initial condition, we do not expect to reproduce the observed ozone and $\mathrm{CO}$ quantitatively but aim to reproduce the mixing behavior and the observed spatial pattern in the vicinity of the STJ. The key questions we aim to address are (1) Can the CLaMS model, using parameterized mixing based on the deformation in the large-scale wind fields, reproduce observed mixing lines? (2) Can the CLaMS simulations (advection with mixing) improve the modeled level of complexity in the spatial structure of the trace gas distribution compared to a pure advection Lagrangian calculation?

[32] Figures 8-10 present comparisons of modeled and observed time series, tracer-tracer relations and the ozone curtain for the case of 971029. In each case, we show the comparisons using model results of advection with and without mixing. The model run was initiated on 971024, 5 days prior to the date of the observations (971029). In the case of mixing, the control parameters are chosen as $\lambda_{c}=$ $1.2\left(\right.$ day $^{-1}$ ) and $\Delta t=12$ (hours), where $\lambda_{\mathrm{c}}$ is the critical Lyapunov exponent and $\Delta t$ is the time interval between each parameterized mixing and regridding, as defined in section 3 . The wind fields used are 4 times daily ECMWF analyses.

[33] Figure 8 shows that both advection with mixing and the pure advection calculation reproduce the observed largescale variation in the time series, represented by the high ozone and low CO inside the cutoff low and vice versa outside. The most significant discrepancy is a segment centered around 1345 UT. The possible cause of this discrepancy will be discussed later in association with Figure 10. There is a significant difference in the smallscale variation between the results with and without mixing with the former agreeing much better with the observations. The pure advection calculation produces unrealistic finescale structures. Note that this is similar to the case of using the reverse domain filling method [Sutton et al., 1994] and the contour advection [Waugh and Plumb, 1994]; while these methods can successfully reconstruct the fine-scale structure using large-scale winds, they can also produce unrealistic structures. The length of the calculation that optimizes the agreement between the calculated and observed variability often depends on the physical conditions of the case under investigation. Subjective selections of length of the advection calculation are often required. We have tested different lengths of simulation using the advection with mixing calculation (between 5 and 25 days), and the results indicate that it is relatively robust and insensitive to the length of simulation.

[34] Figure 9 shows the comparisons of observed and modeled $\mathrm{O}_{3}-\mathrm{CO}$ relationship for the segment of the flight during the second transect of the cutoff low. Figure 9 highlights the main advantage of the CLaMS model over other pure advection Lagrangian models. While the pure advection model is incapable of representing the change in the parcels' chemical content during the advection, the CLaMS reproduces the mixing of the tracers. Figure 9 (left) shows the results of advection and mixing calculation of the tracers, where the observed $\mathrm{O}_{3}-\mathrm{CO}$ relationship is well 

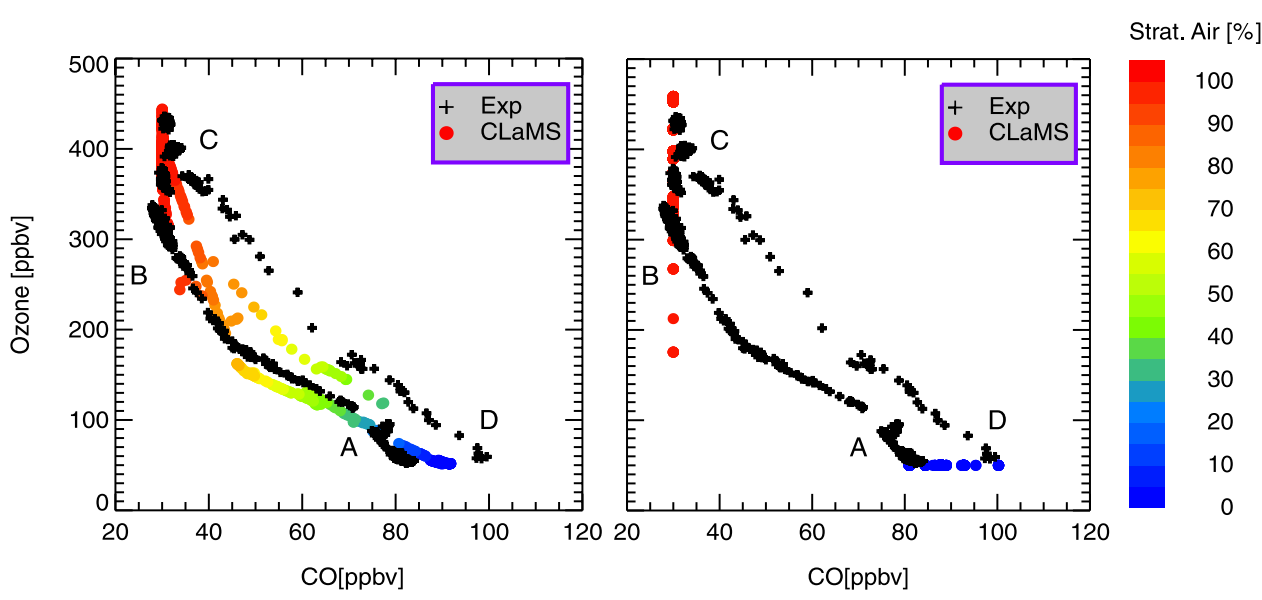

Figure 9. CLaMS simulation of the observed mixing lines. The black crosses are measurements, same as in Figure 6. The colored dots are CLaMS results. The colors indicate the value of stratospheric tracer, as given in the color bar. Result of (left) advection with mixing and (right) pure advection. The letters are the same as in Figure 6.

reproduced. In Figure 9 (right), as a result of pure advection, the tracer relationships just reflect the initial conditions.

[35] The significance of this successful simulation of the observed mixing line is that we can now quantify the cumulative effect of mixing. Using the stratospheric tracer, we can now quantify the percent of the stratospheric air along the mixing line. As shown in Figure 9, the segment between $\mathrm{B}$ and $\mathrm{C}$ is nearly $100 \%$ stratospheric, and the segments between A and B, C and D transition from 100\% to $0 \%$ stratospheric air. This is consistent with the analyses shown in Figures 5 and 6 that the region of mixing expands in the tracer-tracer space.

[36] Comparisons of observed and modeled ozone curtains further support the importance of mixing in reproducing the observed chemical distribution. As shown in Figure 10, the simulation of advection and mixing produces much better agreement with the observation in terms of the spatial variability of the ozone curtain (shown in potential temperature coordinates). As mentioned earlier, we do not expect quantitative agreement for the comparison, because of our oversimplified initial values. Rather, we look for the variability across the tropopause near the STJ. The important feature there is that the model reproduces the transition between stratosphere and troposphere well.

[37] As in Figure 8, a significant disagreement between model and observation exists in the upper troposphere between 1300 and 1500 UT hours, when the DC-8 sampled the vicinity of a branch of the STJ, as indicated by the PV field in Figure 2. The influence of stratospheric air and the downward mixing that elevated the ozone level in the surrounding upper troposphere during that segment of the flight is observable in the lidar curtain data (Figures $4 \mathrm{a}$ and 10a). The model produced a higher level of stratospheric influence on the upper tropospheric ozone. There are two possible reasons for this disagreement. One is the potential errors in the analyzed wind field. It is possible that the spatial extent of the tongue of stratospheric air is not as close to the flight track as shown in Figure 1b. The other factor could be that the lack of convective process in the analyzed field caused the over estimate of downward mixing.
[38] Finally, it is important to find out whether the model parameters selected for the stratospheric cases are applicable in the UTLS region or how the optimized parameters in these two regions differ. In the stratospheric studies, the model parameters were selected by an optimization procedure discussed in detail by Konopka et al. [2004]. The basic idea of the procedure is to minimize the difference between the modeled and observed time series and tracer relationships, i.e., to simultaneously minimize the difference between the red curve (modeled) and the black curve (measured) in Figure 8, and the colored (modeled) points and black (measured) points in Figure 9. Using this procedure, a range of parameters is shown to work well $\left(r_{0} \sim 100-300 \mathrm{~km}, \alpha=250 \pm 100, \lambda_{\mathrm{c}} \Delta t \sim 0.8-\right.$ 1.5). Note that the stratospheric studies show that the results largely depend on the product of $\lambda_{c} \Delta t$. [Konopka et al., 2004, 2005].

[39] In the UTLS region, we have performed the model runs for longer time period ( 2 years), with more realistic initial conditions, to investigate the effect of a range of model parameters. The results, in comparisons with the airborne in situ measurements during SPURT experiment, show that the optimal model parameters are very similar to that derived from the stratospheric studies. These results are content of a follow up paper (P. Konopka et al., manuscript in preparation, 2006). In the case studies presented here, we choose to address the issue how the ClaMS mixing scheme improves over the results of pure trajectory calculations, which is typically carried out for $\sim 5$ days in duration. Because of the short duration and idealized initial conditions, the parameters are chosen to have slightly stronger mixing $\left(\lambda_{\mathrm{c}}=1.2\left(\mathrm{day}^{-1}\right)\right.$ and $\Delta t=12$ (hour), as given at the beginning of this section). This is a demonstration of the applicability of CLaMS in the UTLS region. A more in depth understanding of optimizing this model for the UTLS region requires further studies.

[40] Using the large-scale analyzed winds, the model successfully reproduced the overall features of the chemical distribution (i.e., Figure 10a), indicating the dominant role of large-scale winds. The details of the spatial pattern, however, are not accurately reproduced, which suggest a 

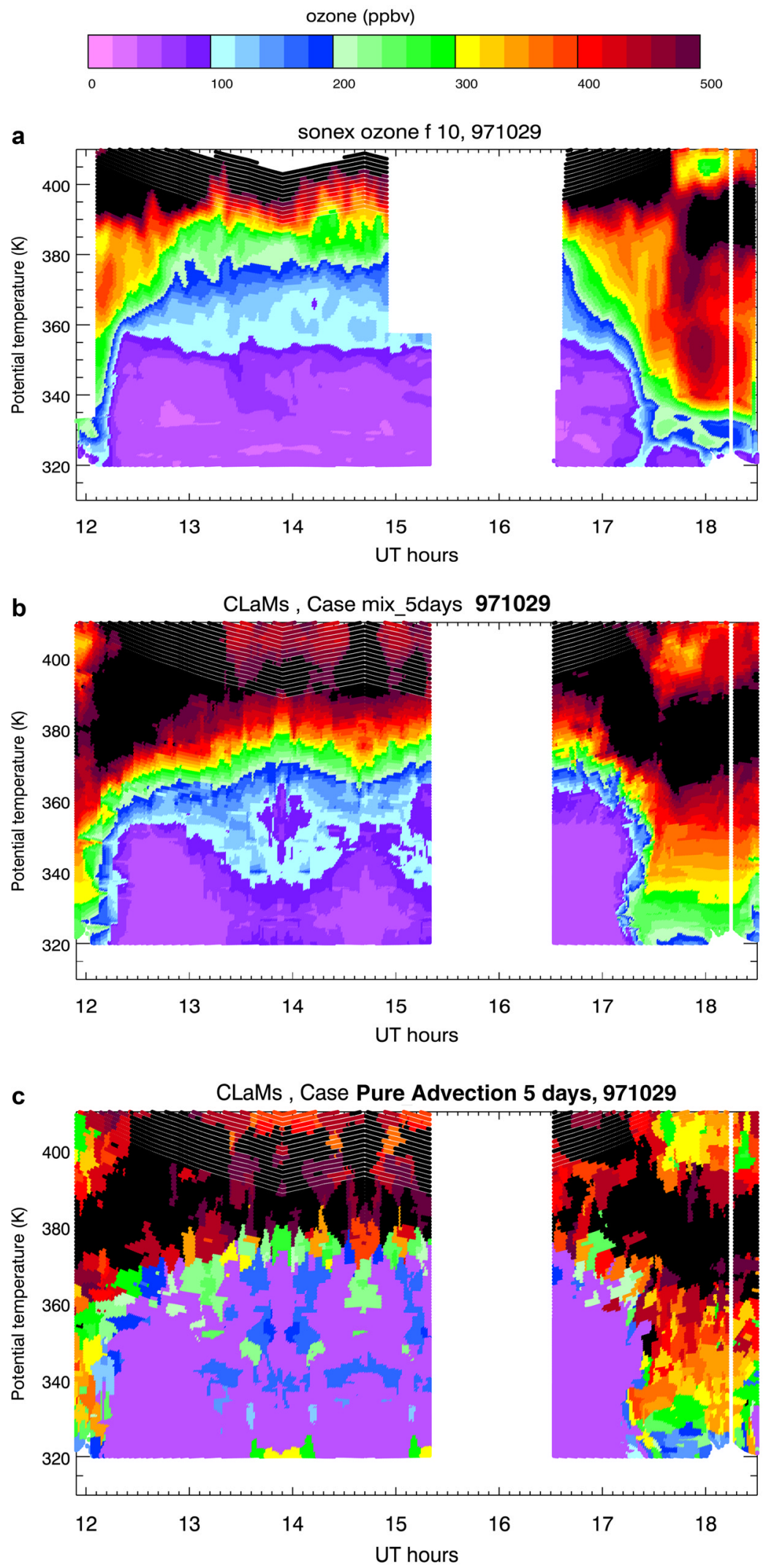

Figure 10. Comparisons of observed and modeled lidar ozone curtain. (a) Same as Figure 4, but using potential temperature as the vertical coordinates. (b) A 5 day CLaMS simulation with advection and mixing. (c) Same 5 day simulation with pure advection. 

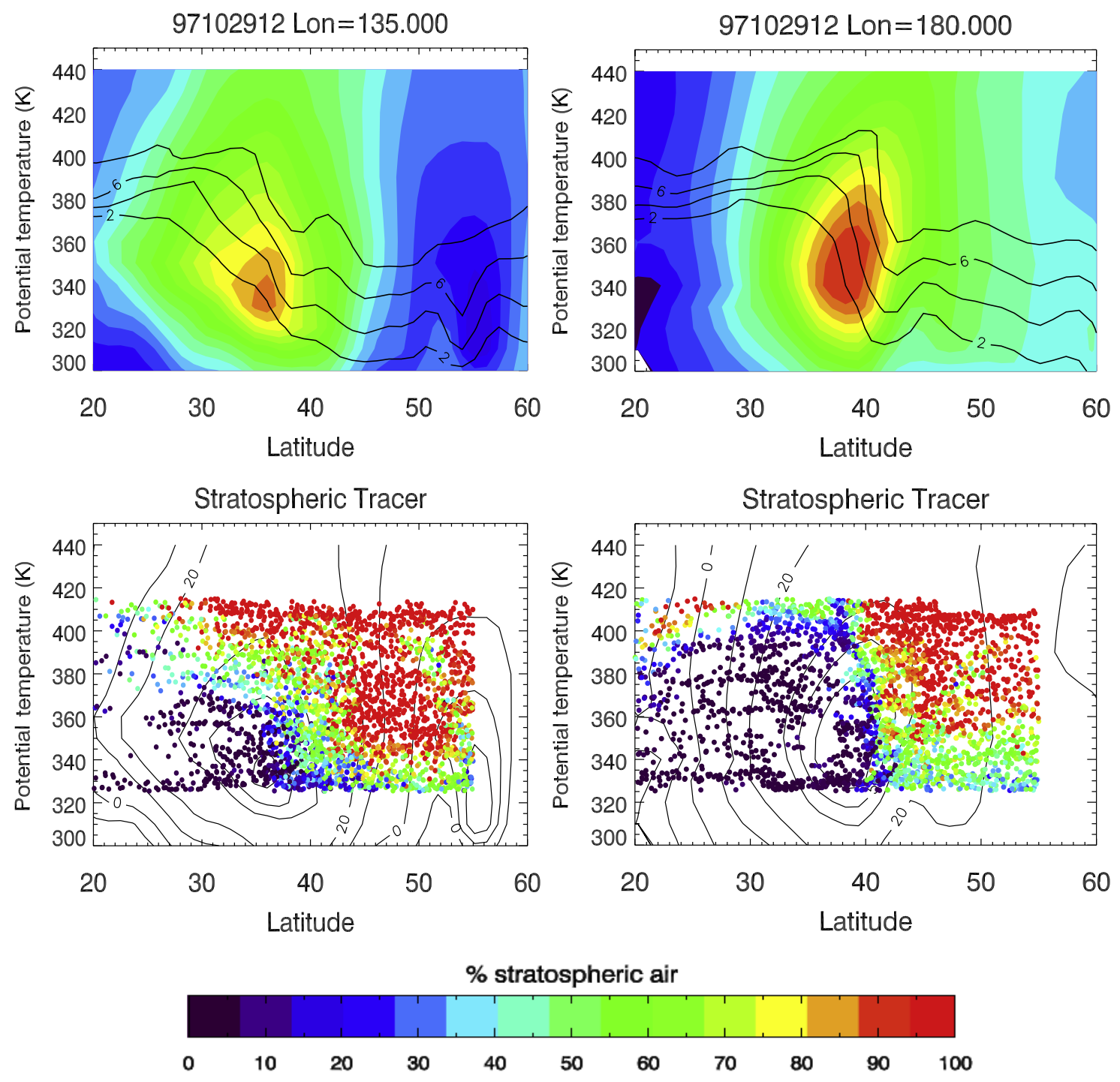

Figure 11. (top) Vertical cross sections of zonal wind (color image) and potential vorticity (black contours represent 2, 4, 6, and 8 PVU isopleths) from ECMWF data. The subtropical jet location and spatial extent is indicated by the wind maximum. Outside the tropics, the 2 PVU potential vorticity contour approximately represents the tropopause. (bottom) Model simulations of mixing near the STJ using model tracer, initialized to be 1 above the tropopause (red), and 0 below the tropopause (purple) (similar to Figure 7b). (right) A case of a strong jet, where the jet core has a barrier effect to isentropic mixing for a large range of potential temperature. (left) A cross section near a relatively weak jet.

role for small-scale processes such as turbulence associated with gravity wave breaking and convection.

\section{Mixing in the Vicinity of the STJ From the Model}

[41] The comparisons presented in the previous section demonstrate the CLaMS model's ability to simulate mixing in the region of the extratropical tropopause. In this section, we further explore the use of the model tracer and the potential of using this model to characterize mixing on a global scale.

[42] As shown in Figure 9, using a stratospheric tracer initiated in the model, we can quantify the percent of stratospheric air along the mixing line. Similarly, we can use this tracer to examine the preferred location and cumulative effect of mixing to the air mass in the vicinity of the jet. Figure 11 shows two latitude-height cross sections (at $135^{\circ} \mathrm{E}$ and $180^{\circ} \mathrm{E}$ ) of the CLaMS stratospheric tracer, together with the zonal wind distributions. In both cases, there is a well-defined subtropical jet, centered near $38^{\circ} \mathrm{N}$, but with different strengths. The left plots of Figure 11 give a case of a relatively weak jet $\left(135^{\circ} \mathrm{E}\right)$. The right plots show a case of a strong jet $\left(180^{\circ} \mathrm{E}\right)$. The values of CLaMS stratospheric tracer, show the effect of mixing to the air mass composition. The stratospheric tracers are initialized to be 1 above the tropopause and 0 below (similar to that is shown in Figure $7 \mathrm{~b}$ but replace the stratospheric part by red and tropospheric part by purple). In this case, the model was initialized on 971004 and model parameter to 
control mixing is set to be $\lambda_{\mathrm{c}}=1.2\left(\mathrm{day}^{-1}\right)$ and $\Delta \mathrm{t}=24$ (hour). These are values similar to that used in the stratosphere studies. Figure 11 shows two cross sections of percentage of the stratospheric air after 25 days, which highlights where mixing has the most effect on the air mass composition in relation to the wind field. In the case of a strong jet, there is a sharp gradient in the tracer across the jet core. The gradient is more smeared in the weaker jet case and a significant part of the air mass show a mixture of stratospheric and tropospheric air, where the percentage of stratospheric air is between 0 and 100 percent. This is consistent with ozone observations across the jet [e.g., Ray et al., 2004]. In both cases, mixing occur on top of the jet and on the cyclonic side of the jet below the jet core.

[43] This example also provides a complementary view of mixing in and around the STJ to some prior studies that used an effective length or effective diffusivity approach [e.g., Haynes and Shuckburgh, 2000]. As indicated by the stratospheric tracer distribution, although the core of the jet appears to be a place of minimum mixing, the mixing of stratosphere and troposphere air does happen across and around the jet, with its cumulated effect most prominent on the top of the jet and at the cyclonic side of the jet, below the jet core.

[44] Using this model tracer, the impact of mixing on air mass composition can be calculated on a seasonal and zonal mean scale, which is the focus of a follow up paper (P. Konopka et al., manuscript in preparation, 2006).

\section{Conclusions and Discussion}

[45] We have presented a study of mixing using both observations and models. The main objective of this study is to investigate an approach to model irreversible STE in the extratropics. A secondary objective is to demonstrate a data analysis approach for identifying the air mass involved in irreversible STE. The key findings of this study are summarized below.

[46] In the data analyses, we have demonstrated the value of mapping the mixing line from the tracer-tracer space to the geophysical space using both tracer measurements and the 2-D cross-section measurements. This approach helps identify the spatial extent of the mixing and irreversible exchange and provide a broader chemical and thermal background for the frequently observed mixing lines. We have shown that the tracer-tracer correlation and lidar curtain are complementary to each other in addressing the issue of how much air mass is involved in irreversible exchange. This approach can be used in the analyses of the new generation of satellite data, where multiple tracers are available for the tropopause region. This approach can also be considered in designing future airborne experiments for STE studies.

[47] The results we have shown demonstrate that, using the deformation in the large-scale winds, the CLaMS model is able to reproduce the overall features of a stratospheric intrusion and the observed mixing lines. This is an important step in modeling STE using the Lagrangian approach. Comparisons between advection with mixing and pure advection results show the significance of mixing in producing the chemical transition and the observed structural complexity in this region. The comparisons support the approach of determining the air mass's irreversible change by physical criteria, such as the deformation in the wind field. This is a better criterion than the use of residence time or depth of intrusion, since the time for irreversible change to occur to an air parcel is likely to be different depending on the dynamical processes involved.

[48] Accurate modeling of the detailed structure in the transition region may require inclusion of additional mechanisms that are not included in the large-scale analyzed winds. Although it is not the objective of this paper to investigate what other processes are responsible for the observed mixing, we speculate that turbulence induced by gravity wave breaking can play a major role. This is based on the observations of the fine-scale structure of the data, both in MTP measured isentropes and in situ chemical tracers, which show rapid oscillations similar in characteristics to the case studies where turbulence induced by gravity wave breaking was identified [Cho et al., 1999; Pavelin et al., 2002]. In particular, Cho et al. [1999] has shown in a case study using also SONEX data that turbulent mixing occurred as a result of both wind shear induced dynamic instability and convective instability in the vicinity of the jet. Additional evidence of mixing induced by gravity wave breaking in the vicinity of the tropopause can be found in Lamarque et al. [1996], Pavelin and Whiteway [2002], and Pavelin et al. [2002]. To characterize the relative importance of the role of small versus large-scale processes, future field experiments with measurement capability to map out the region of turbulence and to capture mixing in the chemical tracer fields, combined with model studies, such as CLaMS, will be a desirable next step.

[49] Using a model tracer, we have shown how the model may be used to characterize mixing between stratospheric and tropospheric air on a global scale. These initial results show the value of this model tracer in identifying preferred mixing regions and the cumulative effect of mixing to both sides of the tropopause. How well this approach may work in quantifying the seasonal cycle of mixing and the limitation of using only the large-scale wind field to parameterize mixing will require further studies.

[50] Acknowledgments. This work is supported in part by the National Science Foundation through its support to the University Corporation for Atmospheric Research (UCAR). The authors thank B. Gary for multiple discussions on the MTP measurements and the derived tropopause heights. We also thank J. Stanford, D. McKenna, R. Garcia, S. Schauffler, and W. Randel for helpful discussions.

\section{References}

Browell, E. V., et al. (1983), NASA multipurpose airborne DIAL system and measurements of ozone and aerosol profiles, Appl. Opt., 22, 522534.

Browell, E. V., E. F. Danielsen, S. Ismail, G. L. Gregory, and S. M. Beck (1987), Tropopause fold structure determined from airborne lidar and in situ measurements, J. Geophys. Res., 92, 2112-2120.

Browell, E. V., S. Ismail, and W. B. Grant (1998), Differential Absorption Lidar (DIAL) measurements from air and space, Appl. Phy. B, 67, 399410.

Cho, J. Y. N., et al. (1999), Observations of convective and dynamical instabilities in tropopause folds and their contribution to stratospheretroposphere exchange, J. Geophys. Res., 104, 21,549-21,568.

Danielsen, E. F. (1968), Stratospheric-tropospheric exchange based on radioactivity, ozone and potential vorticity, J. Atmos. Sci., 25, 502518 . 
Fischer, H., F. G. Wienhold, P. Hoor, O. Bujok, C. Schiller, P. Siegmund, M. Ambaum, H. A. Scheeren, and J. Lelieveld (2000), Tracer correlations in the northern high latitude lowermost stratosphere: Influence of crosstropopause mass exchange, Geophys. Res. Lett., 27, 97-100.

Flentje, H., A. Dörnbrack, G. Ehret, A. Fix, C. Kiemle, G. Poberaj, and M. Wirth (2005), Water vapor heterogeneity related to tropopause folds over the North Atlantic revealed by airborne water vapor differential absorption lidar, J. Geophys. Res., 110, D03115, doi:10.1029/ 2004JD004957.

Grooß, J.-U., and J. M. Russell (2005), Technical note: A stratospheric climatology for $\mathrm{O}_{3}, \mathrm{H}_{2} \mathrm{O}$ and $\mathrm{CH}_{4}$ derived from HALOE measurements, Atmos. Chem. Phys. Disc., 5, 2973-2988.

Haynes, P., and E. Shuckburgh (2000), Effective diffusivity as a diagnostic of atmospheric transport: 1. Stratosphere, J. Geophys. Res., 105(D18), $22,777-22,794$.

Holton, J. R., P. H. Haynes, M. E. McIntyre, A. R. Douglass, R. B. Rood, and L. Pfister (1995), Stratosphere-troposphere exchange, Rev. Geophys., $33,403-439$.

Hoor, P., H. Fischer, L. Lange, J. Lelieveld, and D. Brunner (2002), Seasonal variations of a mixing layer in the lowermost stratosphere as identified by the $\mathrm{CO}-\mathrm{O}_{3}$ correlation from in situ measurements, J. Geophys. Res., 107(D5), 4044, doi:10.1029/2000JD000289.

Hoor, P., C. Gurk, D. Brunner, M. I. Hegglin, H. Wernli, and H. Fischer (2004), Seasonality and extent of extratropical TST derived from in-situ CO measurements during SPURT, Atmos. Chem. Phys. Disc., 4, $1691-$ 1726.

Konopka, P., et al. (2004), Mixing and ozone loss in the 1999-2000 Arctic vortex: Simulations with the 3-dimensional Chemical Lagrangian Model of the Stratosphere (CLaMS), J. Geophys. Res., 109, D02315, doi:10.1029/2003JD003792.

Konopka, P., G. Günther, D. S. McKenna, R. Müller, D. Offermann, R. Spang, and M. Riese (2005), How homogeneous and isotropic is stratospheric mixing?: Comparison of CRISTA-1 observations with transport studies based on the Chemical Lagrangian Model of the Stratosphere (CLaMS), Q. J. R. Meteorol. Soc., 131, 565-579, doi:10.1256/ qj.04.47.

Krebsbach, M., C. Schiller, D. Brunner, G. Guenther, M. I. Hegglin, D. Mottaghy, M. Riese, N. Spelten, and H. Wernli (2006), Seasonal cycles and variability of $\mathrm{O}_{3}$ and $\mathrm{H}_{2} \mathrm{O}$ in the UT/LMS during SPURT, Atmos. Chem. Phys., 6, 109-125.

Lamarque, J.-F., and P. G. Hess (1994), Cross-tropopause mass exchange and potential vorticity budget in a simulated tropopause folding, J. Atmos. Sci., 51, 2246-2269.

Lamarque, J.-F., A. O. Langford, and M. H. Proffitt (1996), Crosstropopause mixing of ozone through gravity wave breaking: Observation and modeling, J. Geophys. Res., 101, 22,969-22,976.

McKenna, D. S., P. Konopka, J. Grooß, G. Günther, R. Müller, R. Spang, D. Offermann, and Y. Orsolini (2002a), A new Chemical Lagrangian Model of the Stratosphere (CLaMS): 1. Formulation of advection and mixing, J. Geophys. Res., 107(D16), 4309, doi:10.1029/2000JD000114.

McKenna, D. S., J. Grooß, G. Günther, P. Konopka, R. Müller, G. Carver, and Y. Sasano (2002b), A new Chemical Lagrangian Model of the Stratosphere (CLaMS): 2. Formulation of chemistry scheme and initialization, J. Geophys. Res., 107(D15), 4256, doi:10.1029/2000JD000113.

Nash, E. R., P. A. Newman, J. E. Rosenfield, and M. R. Schoeberl (1996), An objective determination of the polar vortex using Ertel's potential vorticity, J. Geophys. Res., 101(D5), 9471-9478.
Pan, L. L., W. J. Randel, B. L. Gary, M. J. Mahoney, and E. J. Hintsa (2004), Definitions and sharpness of the extratropical tropopause: A trace gas perspective, J. Geophys. Res., 109, D23103, doi:10.1029/ 2004JD004982.

Pavelin, E., and J. A. Whiteway (2002), Gravity wave interactions around the jet stream, Geophys. Res. Lett., 29(21), 2024, doi:10.1029/ 2002 GL015783.

Pavelin, E., J. A. Whiteway, R. Busen, and J. Hacker (2002), Airborne observations of turbulence, mixing, and gravity waves in the tropopause region, J. Geophys. Res., 107(D10), 4084, doi:10.1029/2001JD000775.

Pfister, L., H. B. Selkirk, E. J. Jensen, J. Podolske, G. Sachse, M. Avery, M. R. Schoeberl, M. J. Mahoney, and E. Richard (2002), Processes controlling water vapor in the winter Arctic tropopause region, J. Geophys. Res., 108(D5), 8314, doi:10.1029/2001JD001067.

Ray, E. A., K. H. Rosenlof, E. Richard, D. Parrish, and R. Jakoubek (2004), Distributions of ozone in the region of the subtropical jet: An analysis of in situ aircraft measurements, J. Geophys. Res., 109, D08106, doi:10.1029/2003JD004143.

Sachse, G. W., G. F. Hill, L. O. Wade, and M. G. Perry (1987), Fastresponse, high precision carbon monoxide sensor using a tunable diode laser absorption technique, J. Geophys. Res., 92, 2071-2081.

Shapiro, M. A. (1980), Turbulent mixing within tropopause folds as a mechanism for the exchange of chemical constituents between the stratosphere and troposphere, J. Atmos. Sci., 37, 994-1004.

Singh, H. B., A. M. Thompson, and H. Schlager (1999), SONEX airborne mission and coordinated POLINAT-2 activity: Overview and accomplishments, Geophys. Res. Lett., 26(20), 3053-3056.

Stohl, A. (2003), Stratosphere-troposphere exchange: A review, and what we have learned form STACCATO, J. Geophys. Res., 108(D12), 8516, doi:10.1029/2002JD002490.

Sutton, R. T., H. Maclean, R. Swinbank, A. O’Neill, and F. W. Taylor (1994), High-resolution stratospheric tracer fields estimated from satellite observations using Lagrangian trajectory calculations, J. Atmos. Sci., 51, 2995-3005.

Waugh, D. W., and R. A. Plumb (1994), Contour advection with surgery: A technique for investigating finescale structure in tracer transport, J. Atmos. Sci., 51, 530-540.

Wernli, H., and M. Bourqui (2002), A Lagrangian "1-year climatology" of (deep) cross-tropopause exchange in the extratropical Northern Hemisphere, J. Geophys. Res., 107(D2), 4021, doi:10.1029/2001JD000812.

Wimmers, A. J., et al. (2003), Signatures of tropopause folding in satellite imagery, J. Geophys. Res., 108(D4), 8360, doi:10.1029/2001JD001358. World Meteorological Organization (1986), Atmospheric ozone 1985 , WMO Global Ozone Res. Monit. Proj. Rep. 20, Geneva, Switzerland.

Zahn, A., et al. (2000), Identification of extratropical two-way tropospherestratosphere mixing based on CARIBIC measurements of $\mathrm{O}_{3}, \mathrm{CO}$, and ultrafine particles, J. Geophys. Res., 105, 1527-1535.

E. V. Browell, NASA Langley Research Center, Hampton, VA 23681, USA.

P. Konopka, Institute for Stratospheric Chemistry (ICG-I), D-52425 Juelich, Germany.

L. L. Pan, National Center for Atmospheric Research, Boulder, CO 80305, USA. (liwen@ucar.edu) 